\title{
Opinions, barriers and facilitators of injury prevention in recreational
}

\section{runners}

Tryntsje Fokkema, MSc ${ }^{1}$, Robert-Jan de Vos, MD, $\mathbf{P h D}^{2}$, Sita M.A. Bierma-Zeinstra, $\mathrm{PhD}^{1,2}$, Marienke van Middelkoop, $\mathrm{PhD}^{1}$

${ }^{1}$ Department of General Practice, Erasmus MC, University Medical Center Rotterdam, the Netherlands, ${ }^{2}$ Department of Orthopaedics and Sports Medicine, Erasmus MC, University Medical Center Rotterdam, the Netherlands

\section{Corresponding author:}

Tryntsje Fokkema

Erasmus MC, University Medical Center Rotterdam

P.O. Box 2040

3000 CA Rotterdam (the Netherlands)

t.fokkema@erasmusmc.nl

The study was approved by the Medical Ethical Committee of the Erasmus University Medical Center Rotterdam (MEC-2016-292).

This study was funded by the Netherlands Organization for Health Research and Development (ZonMW, 536001001).

Financial Disclosure and Conflict of Interest. We affirm that we have no financial affiliation (including research funding) or involvement with any commercial organization that has a direct financial interest in any matter included in this manuscript or other conflicts of interest. 


\section{Acknowledgements}

The authors would like to thank all runners who participated in the INSPIRE trial and Golazo Sports for its collaboration. 


\section{ABSTRACT}

\section{Study design}

Comparative cross-sectional study

\section{Background}

Effective injury prevention measures for running-related injuries (RRIs) have not yet been identified. More insight into the opinions of runners about injury prevention might help to develop effective injury prevention programs that are supported by the target population.

\section{Objectives}

To describe the opinions of recreational runners on different components of injury prevention and to identify the barriers to and facilitators of injury prevention in adult recreational runners.

\section{Methods}

A single questionnaire was sent to 2378 recreational runners. The questionnaire contained questions about their interests, actions undertaken, and perceived barriers to and facilitators of injury prevention. Descriptive analyses were used to examine differences with regard to sex, age, and previous RRIs.

\section{Results}

1034 adult recreational runners (43.5\%) responded to the questionnaire. Runners with previous RRIs were more likely to rate injury prevention as very useful than runners who had never sustained an RRI (76.8\% vs. $63.6 \%$, $\mathrm{p}<0.001)$. In total, $81.8 \%$ of the participants 
indicated that they already performed preventive measures, including changes to training schedules (65.4\%) and warming-up (57.8\%). Most frequently reported barriers to injury prevention were 'not knowing what to do' (45.2\%) and 'no history of RRI' (34.6\%). The most important facilitator was an injury (60.1\%). Women more often preferred information via a trainer or running store than did men, while men more frequently preferred websites or email.

\section{Conclusion}

The majority of runners rated injury prevention as important. To increase effectiveness, future prevention programs should be developed with an awareness of the barriers and facilitators experienced by adult runners. 


\section{INTRODUCTION}

Running is a sport that is practiced frequently and is still growing in popularity ${ }^{1}$. This is probably because running is an easily accessible and inexpensive sport that can yield fast improvements in physical fitness ${ }^{2,3}$. However, a major drawback of running is the high number of running-related injuries (RRIs). A systematic review from 2015 showed that injury proportions range from 3.2-84.9\% in adult runners in studies with a follow-up time or recall period between 1 day and lifetime. These percentages indicate a necessity for effective RRI prevention measures ${ }^{4}$. In the last few decades, several randomized trials on RRI prevention have been performed ${ }^{5-11}$. However, in most trials no significant reduction in the number of RRIs was effectuated.

According to the Translating Research into Injury Prevention Practice (TRIPP) framework of Finch, identifying etiologic factors that are readily modifiable and consistent with a biological mechanism is important to preventing RRIs ${ }^{12}$. As suggested by Bertelsen et al, insights into how factors influence the dose-response relationship between running participation and injuries will likely increase the understanding of the etiology of RRIs ${ }^{13}$. However, insight into the behavioral context in which injury prevention measures will be implemented is necessary for running injury prevention ${ }^{12}$. Taking the attitudes about, barriers to, and facilitators of injury prevention of athletes into account when designing and implementing injury prevention measures may increase the odds of successful injury prevention. Saragiotto et al. explored the beliefs of recreational runners about the most important risk factors for RRIs ${ }^{14}$. They found that runners think that RRIs are mainly related to i) training, ii) running shoes and iii) exceeding the limits of the body, and suggested that these factors should be considered when developing new injury prevention strategies. To increase our understanding of the attitudes about, barriers to and facilitators of injury prevention, this exploratory study aimed to i) describe the opinions of adult recreational 
runners on different components of injury prevention and compare the opinions of different subgroups of runners, and to ii) identify the barriers to and facilitators of injury prevention in these runners.

\section{METHODS}

This study is part of the INtervention Study on Prevention of Injuries in Runners at Erasmus [Medical Center] (INSPIRE) trial, a randomized-controlled trial (RCT) on the effectiveness of a multifactorial online RRI prevention program ${ }^{15}$. Recreational runners 18 years or older who registered in 2017 for one of three selected running events (distances ranging from 5-42.2 km) were invited to participate in the trial. Participants in the intervention group were given access to the online injury prevention program, which consisted of information on evidence-based risk factors and advice on how to reduce injury risk. Participants in the control group followed their regular preparation for the running event. With three follow-up questionnaires, the effectiveness of the prevention program on the number of RRIs was evaluated. In the INSPIRE trial an RRI was defined as an injury of the muscles, joints, tendons and/or bones in the lower back or lower extremities (hip, groin, thigh, knee, leg, ankle, foot and toes) that was caused by running. Furthermore, one of the following criteria had to be met: i) the injury was severe enough to cause a reduction in running distance, speed, duration or frequency for at least 1 week; ii) the injury led to a visit to a doctor and/or physiotherapist; or iii) medication was necessary to reduce symptoms as a result of the injury. More details on the INSPIRE-trial are published elsewhere ${ }^{15}$. The INSPIRE trial was funded by the Netherlands Organization for Health Research and Development (ZonMW, 536001001) and was performed in collaboration with Golazo Sports, a company that organizes large running events in the Netherlands This study was approved by the Medical Ethics Committee of the Erasmus University Medical 
Center Rotterdam (MEC-2016-292). The participants signed an informed-consent form before participating and their rights were protected.

Approximately seven months after the running event, all participants in both the intervention group and control group received an implementation questionnaire containing questions about their interests, preventive actions undertaken, and barriers to and facilitators of injury prevention. For the present study, only data from these implementation questionnaires were used.

The implementation questionnaire consisted of four sections. First, information about the runners was collected: sex, date of birth, years of running experience, average running frequency and training volume per week and previous RRIs. The second section contained questions on RRI prevention. The runners were asked about the factors they thought were important in RRI prevention: healthy lifestyle, running clothes, running shoes, progression of the training program, running technique, running surface and/or other. The attitude towards the usefulness of RRI prevention was also captured in this section (very useful, a little useful, or not useful). The participants were asked whether they ever searched for RRI prevention measures (yes or no). Next, they were asked whether they actively performed RRI prevention measures themselves (yes or no). If so, more information on the type of measures was obtained: healthier lifestyle, changes to the training schedule, warming-up/cooling-down, stretching, changes to clothes, changes to shoes, insoles/orthotics, bandages/braces/taping, compression socks, running surface, changes in running technique and/or other. In the last section, information on barriers to and facilitators of RRI prevention was obtained. The runners who did not perform preventive measures were asked about the most important barriers to injury prevention (never had an injury, no time, not useful, not amusing, not motivated, does not fit into my training schedule, do not know what to do and/or other) and facilitators of injury prevention (an RRI, attractive offer of information on prevention, better 
access to information on RRI prevention, integration into daily training, more knowledge of effectiveness, improving running performance, financial compensation, free supplies for RRI prevention and/or other). Finally, participants were asked for their preferred ways to receive information on RRI prevention (mobile application, website, e-mail, trainer, running store, magazine, health professional and/or other).

Differences in characteristics between the participants in the INSPIRE-trial who did and did not respond to the implementation questionnaire were determined using independent sample t-tests and chi-square tests. For all data collected, means and standard deviations (SD) (continuous data), or frequencies and percentages (categorical data) were calculated. To test the impact of the injury prevention program of the INSPIRE-trial on the answers to the implementation questionnaire, the responses of participants in the intervention group were compared with those of the control group. Furthermore, subgroup analyses were performed for sex, age (younger than 35 years, 35 to 50 years and older than 50 years), and previous injuries (yes or no). Subgroup differences were tested using chi-square tests. Analyses were performed in SPSS Statistics 24 (IBM Corporation, Armonk, NY), and a $P$ value less than .05 was regarded as statistically significant.

\section{RESULTS}

In total, 2378 adult recreational runners participated in the INSPIRE-trial, of whom $43.5 \%$ (1034 runners) completed the implementation questionnaire. The runners who completed the questionnaire were on average older [44.1 (SD 12.5) vs. 39.8 (SD 11.2) years, $\mathrm{p}<0.001$ ], had more running experience [7.5 (SD 8.8) vs. 5.8 (SD 6.9) years, $\mathrm{p}<0.001$ ] and were more often male (55.5\% vs. 50.4\%, $\mathrm{p}=0.014$ ) than the runners who did not respond to this questionnaire. The characteristics of the participants in this study are shown in Table 1. 
Almost three quarters of the participants (74.1\%; 95\% confidence interval [CI] 71.3, 76.7\%) rated injury prevention as very useful (Table 2). Progression of the training program (94.4\%, 95\% CI 92.8;95.7\%), running shoes (76.4\%, 95\% CI 73.7;78.9\%) and running technique (55.8\%, 95\% CI 52.7; 58.9\%) were reported to be the most important aspects of injury prevention. The majority of the participants (68.4\%, 95\% CI 65.4;71.2\%) actively searched for information on injury prevention and 81.8\% (95\% CI 79.3;84.1\%) performed preventive measures themselves. These preventive measures most often included changes to training schedules (65.4\%, 95\% CI 62.0;68.6\%), warming-up and cooling-down (57.8\%, 95\% CI 54.4;61.1\%), and stretching (49.8\%, 95\% CI 46.3;53.2\%). The most important barriers reported by runners who did not perform injury prevention were 'not knowing what to do' (45.2\%, 95\% CI 38.0;52.6\%) and no history of RRI (34.6\%, 95\% CI 27.9;41.9\%) (Table 3). Their most important reported reason to start injury prevention was an RRI (60.1\%, 95\% CI $52.7 ; 67.1 \%)$. The most important ways to receive information on injury prevention were through mobile applications (49.3\%, 95\% CI 46.2;52.4\%) and websites (45.4\%, 95\% CI $42.3 ; 48.5 \%)$.

Of all responses, only two showed a significant difference between participants in the intervention group and those in the control group of the INSPIRE-trial: runners in the intervention group performed injury prevention measures more often than participants in the control group (84.4\% vs. $79.5 \%, \mathrm{p}=0.041$ ) and more often preferred to receive information through an app (52.7\% vs. $46.2 \%, \mathrm{p}=0.036)$.

The results of the subgroup analyses are presented in Tables 2 and 3. Men more often preferred to receive information on injury prevention through websites (49.2\% vs. $40.5 \%$, $\mathrm{p}=0.005$ ) or e-mail (36.4\% vs. $29.3 \%, \mathrm{p}=0.017)$ than women, while women more frequently preferred to receive the information personally via a trainer $(43.5 \%$ vs. $31.0 \%$, $\mathrm{p}<0.001)$ or at a running store (19.0\% vs. $11.8 \%, \mathrm{p}=0.001)$. More runners aged under 35 years would start 
taking injury prevention measures if they would receive financial compensation (15.2\% vs. $0.0 \%$ and $1.8 \%, \mathrm{p}<0.001$ ) or free supplies (34.8\% vs. $9.2 \%$ and $12.3 \%, \mathrm{p}<0.001$ ) for injury prevention. Runners with a history of RRI more often experienced a lack of motivation (25.2\% vs. $12.3 \%, \mathrm{p}=0.032)$ and 'not knowing what to do' (59.1\% vs. $23.3 \%, \mathrm{p}<0.001)$ as barriers to injury prevention than did runners who had not suffered an RRI in the past.

\section{DISCUSSION}

The aims of this study were to describe the opinions of adult recreational runners on different components of injury prevention and compare the opinions of different subgroups of runners, and to identify the barriers to and facilitators of injury prevention in these runners. The large majority of participants regarded injury prevention as very useful. The most important barriers for injury prevention were 'not knowing what to do' and 'no history of RRI', while sustaining an RRI was the most important facilitator of injury prevention. Mobile applications and websites were the most preferred ways to receive information on injury prevention.

Injury prevention is important to recreational runners. In the present study, almost $70 \%$ of the runners reported actively searching for information on injury prevention, and over 80\% reported performing injury prevention measures themselves. However, the number of RRIs among recreational runners is high, indicating that the injury prevention measures undertaken may not have the intended effect ${ }^{4}$. In this study, recreational runners' opinions on the most important aspects of injury prevention were comparable to those reported by Saragiotto et al. regarding risk factors ${ }^{14}$. In both studies, training, running technique and running shoes were regarded as important aspects for injury prevention. Some of these aspects correspond to the actual risk factors for RRIs; for example, different aspects of training and running technique are known to be risk factors for sustaining an $\mathrm{RRI}^{16-18}$. However, the fact that running shoes were also regarded as an important aspect for injury prevention is probably 
because shoe manufacturers and running stores generally aim to make runners believe that wearing a certain type of shoe can prevent injuries. There is an ongoing debate regarding the relationship between running shoes and RRIs; nevertheless it has never been demonstrated that RRIs can be prevented by wearing a certain type of shoe or by matching shoe type to foot morphology $y^{19,20}$. According to the TRIPP framework of Finch, injury prevention measures should be implemented with awareness of the attitudes of runners toward injury prevention ${ }^{12}$. Therefore, future injury prevention programs should be designed with awareness of the above-mentioned ideas of runners themselves about the most important aspects of injury prevention. Runners should also be informed that there is evidence against the effectiveness of injury prevention via the 'prescription' of specific shoes based on the runner's foot type ${ }^{19}$. However, more research is needed to increase our understanding of how and why RRIs occur and to optimize both the content and context of injury prevention measures ${ }^{13}$. In the present study, compared with runners who had suffered an RRI, runners without a history of RRI seemed less interested in injury prevention than runners who had an RRI in the past (ie, they rated the usefulness of injury prevention lower and performed fewer preventive actions themselves). Furthermore, an RRI was rated as the most important facilitator for injury prevention. Therefore, runners with a history of RRI seem to have a higher intrinsic motivation for injury prevention. However, runners with a history of RRI may also benefit most from injury prevention measures, because a previous RRI is the most important risk factor for a new $\mathrm{RRI}^{1,3,21}$. Therefore, future research on injury prevention could possibly target runners with a previous RRI.

In this study a relatively high percentage of runners (81.8\%) performed injury prevention measures. This may be partly related to the fact that the runners participated in an RCT on injury prevention. Runners who are not interested in injury prevention would probably not have participated in this RCT and the injury prevention program may have motivated runners 
in the intervention group to perform injury prevention measures. However, the high percentage of runners in the control group (79.5\%) who performed injury_prevention measures indicates that many recreational runners perform injury prevention measures. This is important to realize when designing a new RCT on injury prevention. It might make it more difficult to test the effectiveness of injury prevention measures, as it is unlikely that a control group would include only runners who have never performed any injury prevention measure.

According to the TRIPP framework of Finch, injury prevention measures should be implemented with awareness of the most important barriers to and facilitators of injury prevention experienced by recreational runners ${ }^{12}$. Because the most frequently mentioned barrier was 'not knowing what to do', future prevention measures should include clear and practical information on injury prevention. An important facilitator was 'more knowledge on the effectiveness of the prevention program'. Unfortunately, it is impossible to provide such information on a new injury prevention measure that has yet to be tested. However, runners could be informed that the injury prevention measures are, for example, related to risk factors for RRIs and are therefore designed to decrease the number of RRIs. Also the preferred ways to receive information on injury prevention should be taken into account. Running is an individual sport and most runners preferred to receive information on injury prevention in an individual way. Mobile applications and websites were the preferred ways to receive information on injury prevention and, therefore, future injury prevention measures could be delivered via these mediums. Personal ways to deliver information (e.g. via a trainer or at a running store) might also be used when targeting women.

\section{Strengths and limitations}

A strength of this study is that, to our knowledge, it is the first to investigate the barriers to and facilitators of injury prevention in adult recreational runners. Another strength is the large 
sample size. Nevertheless, some limitations need to be addressed. First, only runners who registered for a running event were included in this study. Even though runners from all levels participated in the selected running event, participants of running events may be more fanatic runners than runners who do not participate in running events, which may have caused some bias in the results. Second, all runners in this study participated in an RCT on injury prevention, which may have biased the results. Because runners who are not interested in injury prevention would probably not participate in an RCT on injury prevention, the percentages of runners who rated injury prevention as useful and who performed injury prevention measures might be higher than in the general running population. Furthermore, runners in the intervention group of the INSPIRE-trial received information about injury prevention, which may have biased their opinion on important aspects of injury prevention. Another limitation is that the questionnaire used multiple-choice answers. These answer options might have biased the participants’ answers to the questions on opinions, barriers, and facilitators by restricting them as opposed to open-ended questions. However, open-ended questions are known to have a higher rate of missing data ${ }^{22}$. Additionally, we provided an "other" option at the end of each question regarding opinions, barriers, and facilitators, which was open-ended and allowed the runners to reflect on their personal beliefs. A fourth limitation is that knowledge of some potential contributors to injury prevention, like nutrition and sleep, was not assessed ${ }^{23,24}$. Another limitation is the relatively low response rate to the implementation questionnaire. More than $50 \%$ of the participants in the INSPIRE-trial did not respond, which may have biased the results of the current study. There were significant differences between the runners who did and did not respond to the implementation questionnaire. Responders were more often male and relatively older runners. However, it should be mentioned that these differences were very small (less than four years in age and slightly more than 5\% more men) and may therefore not be of relevance when designing a 
prevention program. Finally, we did not correct for multiple testing. However, all significant differences between subgroups were large (5.6-84.6\%) and therefore relevant.

\section{Conclusion}

The majority of adult recreational runners reported that injury prevention is important and performed injury prevention measures themselves. According to the TRIPP framework of Finch, it is important to take into account the ideas of runners about injury prevention, as well as the experienced barriers to and facilitators of the implementation of injury prevention measures. Based on the present study, we suggest presenting future injury prevention programs on a mobile application and/or website. For women it might be beneficial to also offer the opportunity to receive information on injury prevention personally (eg, via a trainer or at a running store. Because 'not knowing what to do' was the most important reported barrier to injury prevention, future injury prevention programs should contain clear and practical information that runners can easily apply to their training. Finally, future injury prevention programs may primarily target runners with a history of RRI, because these runners seem more motivated to perform preventive measures than runners with no history of RRI.

\section{Key Points}

Findings: The majority of the adult recreational runners rated injury prevention as very important and performed injury prevention measures themselves. Most frequently reported barriers for injury prevention were 'not knowing what to do' and 'no history of RRI', while the most important facilitator was sustaining an injury.

Implications: To increase effectiveness, future prevention programs should be developed with awareness of the opinions and experienced barriers and facilitators of runners. 
Caution: The runners in this study participated in an RCT on injury prevention; runners who were not interested in injury prevention would probably not have participated. Therefore, the percentage of runners who rated injury prevention as useful and who performed injury prevention measures might be overestimated.

\section{References}

1. Bertelsen ML, Hulme A, Petersen J, et al. A framework for the etiology of running-related injuries. Scand J Med Sci Sports 2017;27(11):1170-1180. http://dx.doi.org/10.1111/sms.12883

2. Bredeweg SW, Zijlstra S, Bessem B, Buist I. The effectiveness of a preconditioning programme on preventing running-related injuries in novice runners: a randomised controlled trial. Br J Sports Med 2012;46(12):865-870. http://dx.doi.org/10.1136/bjsports-2012-091397

3. Buist I, Bredeweg SW, van Mechelen W, Lemmink KAPM, Pepping GJ, Diercks RL. No effect of a graded training program on the number of running-related injuries in novice runners. Am J Sport Med 2008;36(1):35-41. http://dx.doi.org/10.1177/0363546507307505

4. De Souza MJ, Williams NI, Nattiv A, et al. Misunderstanding the female athlete triad: refuting the IOC consensus statement on Relative Energy Deficiency in Sport (RED-S). Br J Sports Med 2014;48(20):1461-1465. http://dx.doi.org/10.1136/bjsports-2014-093958

5. Finch C. A new framework for research leading to sports injury prevention. J Sci Med Sport 2006;9(1-2):3-9; discussion 10. http://dx.doi.org/10.1016/j.jsams.2006.02.009

6. Fokkema T, de Vos RJ, van Ochten JM, et al. Preventing running-related injuries using evidence-based online advice: the design of a randomised-controlled trial. BMJ Open Sport Exerc Med 2017;3(1):e000265. http://dx.doi.org/10.1136/bmjsem-2017-000265

7. Hespanhol LC, Jr., van Mechelen W, Verhagen E. Effectiveness of online tailored advice to prevent running-related injuries and promote preventive behaviour in Dutch trail runners: a pragmatic randomised controlled trial. Br J Sports Med 2018;52(13):851-858. http://dx.doi.org/10.1136/bjsports-2016-097025 
8. Kluitenberg B, van Middelkoop M, Diercks R, van der Worp H. What are the Differences in Injury Proportions Between Different Populations of Runners? A Systematic Review and Meta-Analysis. Sports Med 2015;45(8):1143-1161. http://dx.doi.org/10.1007/s40279-015$\underline{0331-x}$

9. Knapik JJ, Trone DW, Tchandja J, Jones BH. Injury-reduction effectiveness of prescribing running shoes on the basis of foot arch height: summary of military investigations. J Orthop Sports Phys Ther 2014;44(10):805-812. http://dx.doi.org/10.2519/jospt.2014.5342

10. Malisoux L, Chambon N, Delattre N, Gueguen N, Urhausen A, Theisen D. Injury risk in runners using standard or motion control shoes: a randomised controlled trial with participant and assessor blinding. Brit J Sport Med 2016;50(8):481-487.

http://dx.doi.org/10.1136/bjsports-2015-095031

11. Malisoux L, Chambon N, Urhausen A, Theisen D. Influence of the Heel-to-Toe Drop of Standard Cushioned Running Shoes on Injury Risk in Leisure-Time Runners: A Randomized Controlled Trial With 6-Month Follow-up. Am J Sports Med 2016;44(11):2933-2940. http://dx.doi.org/10.1177/0363546516654690

12. Malisoux L, Nielsen RO, Urhausen A, Theisen D. A step towards understanding the mechanisms of running-related injuries. J Sci Med Sport 2015;18(5):523-528. http://dx.doi.org/10.1016/j.jsams.2014.07.014

13. Millar MM, Dillman DA. Do Mail and Internet Surveys Produce Different Item Nonresponse Rates? An Experiment Using Random Mode Assignment. Survey Practice 2012;5(2). http://dx.doi.org/10.29115/SP-2012-0011

14. Mountjoy M, Sundgot-Borgen JK, Burke LM, et al. IOC consensus statement on relative energy deficiency in sport (RED-S): 2018 update. Br J Sports Med 2018;52(11):687-697. http://dx.doi.org/10.1136/bjsports-2018-099193

15. Napier C, Willy RW. Logical fallacies in the running shoe debate: let the evidence guide prescription. Br J Sports Med 2018;52(24):1552-1553. http://dx.doi.org/10.1136/bjsports$\underline{2018-100117}$ 
16. Nielsen RO, Buist I, Sorensen H, Lind M, Rasmussen S. Training errors and running related injuries: a systematic review. Int J Sports Phys Ther 2012;7(1):58-75.

17. Saragiotto BT, Yamato TP, Hespanhol Junior LC, Rainbow MJ, Davis IS, Lopes AD. What are the main risk factors for running-related injuries? Sports Med 2014;44(8):1153-1163. http://dx.doi.org/10.1007/s40279-014-0194-6

18. Saragiotto BT, Yamato TP, Lopes AD. What do recreational runners think about risk factors for running injuries? A descriptive study of their beliefs and opinions. J Orthop Sports Phys Ther 2014;44(10):733-738. http://dx.doi.org/10.2519/jospt.2014.5710

19. Theisen D, Malisoux L, Genin J, Delattre N, Seil R, Urhausen A. Influence of midsole hardness of standard cushioned shoes on running-related injury risk. Brit J Sport Med 2014;48(5). http://dx.doi.org/10.1136/bjsports-2013-092613

20. van der Worp MP, ten Haaf DS, van Cingel R, de Wijer A, Nijhuis-van der Sanden MW, Staal JB. Injuries in runners; a systematic review on risk factors and sex differences. PLoS One 2015;10(2):e0114937. http://dx.doi.org/10.1371/journal.pone.0114937

21. van Gent RN, Siem D, van Middelkoop M, van Os AG, Bierma-Zeinstra SM, Koes BW. Incidence and determinants of lower extremity running injuries in long distance runners: a systematic review. Br J Sports Med 2007;41(8):469-480; discussion 480. http://dx.doi.org/10.1136/bjsm.2006.033548

22. Vanmechelen W, Hlobil H, Kemper HCG, Voorn WJ, Dejongh HR. Prevention of Running Injuries by Warm-up, Cool-down, and Stretching Exercises. Am J Sport Med 1993;21(5):711719. http://dx.doi.org/10.1177/036354659302100513

23. Verhagen E. Prevention of running-related injuries in novice runners: are we running on empty? Br J Sports Med 2012;46(12):836-837. http://dx.doi.org/10.1136/bjsports-2012$\underline{091505}$

24. Zadpoor AA, Nikooyan AA. The relationship between lower-extremity stress fractures and the ground reaction force: a systematic review. Clin Biomech (Bristol, Avon) 2011;26(1):23-28. http://dx.doi.org/10.1016/j.clinbiomech.2010.08.005 
Table 1. Mean (SD) or frequencies (\%) of the characteristics of the study participants ( $\mathrm{N}=1034)$. The characteristics are also separately displayed for the analyzed subgroups (males and females, different age groups and runners with and without a history of RRI).

\begin{tabular}{|c|c|c|c|c|c|c|c|c|}
\hline & \multirow[t]{2}{*}{ All participants } & \multicolumn{2}{|c|}{ Sex } & \multicolumn{3}{|c|}{ Age (years) } & \multicolumn{2}{|c|}{ History of RRI* } \\
\hline & & Male & Female & $\leq 35$ & $35-50$ & $\geq 50$ & Yes & No \\
\hline $\mathrm{N}$ & 1034 & 577 (55.8\%) & 457 (44.2\%) & $303(29.3 \%)$ & $381(36.8 \%)$ & $350(33.8 \%)$ & $820(79.3 \%)$ & $214(20.7 \%)$ \\
\hline Sex (male) & $577(55.8 \%)$ & $577(100 \%)$ & $0(0.0 \%)$ & $108(35.3 \%)$ & $214(56.2 \%)$ & 255 (72.9\%) & $471(57.4 \%)$ & $106(49.5 \%)$ \\
\hline Age (years) & $44.1(12.5)$ & $47.8(11.9)$ & $39.4(23.1)$ & $28.7(4.0)$ & $43.5(4.4)$ & $58.0(5.5)$ & $44.6(12.5)$ & $42.2(12.4)$ \\
\hline $\operatorname{BMI}\left(\mathrm{kg} / \mathrm{m}^{2}\right)^{\dagger}$ & $23.7(2.9)$ & $24.1(2.7)$ & $23.1(3.1)$ & $23.1(3.0)$ & $23.7(3.1)$ & $24.1(2.6)$ & $23.8(3.0)$ & $23.4(2.9)$ \\
\hline Running experience (years) & $7.5(8.8)$ & $9.1(10.1)$ & $5.4(6.2)$ & 3.7 (3.5) & $6.1(6.3)$ & $12.3(11.8)$ & $7.8(9.2)$ & $6.2(6.9)$ \\
\hline Running frequency (times/week) & $2.4(1.2)$ & $2.5(1.2)$ & $2.3(1.2)$ & $2.1(1.1)$ & $2.5(1.3)$ & $2.6(1.0)$ & $2.5(1.2)$ & $2.1(1.1)$ \\
\hline Running distance (km/week) & $22.7(15.8)$ & $25.6(16.8)$ & $19.1(13.5)$ & $18.3(14.6)$ & $23.5(16.7)$ & $25.8(14.7)$ & $23.6(15.7)$ & $19.5(15.4)$ \\
\hline Previous RRI (yes) & $820(79.3 \%)$ & $471(81.6 \%)$ & $349(76.4 \%)$ & $236(77.9 \%)$ & $292(76.6 \%)$ & $292(83.4 \%)$ & $820(100 \%)$ & $0(0.0 \%)$ \\
\hline
\end{tabular}

* running-related injury; ${ }^{\dagger}$ Body Mass Index 
Table 2. Opinions of the participants (\%) about the importance of running injury prevention and performing preventive measures

\begin{tabular}{|c|c|c|c|c|c|c|c|c|c|c|c|}
\hline & \multirow{3}{*}{$\begin{array}{l}\text { All participants } \\
\qquad \mathrm{N}=1034\end{array}$} & \multicolumn{2}{|c|}{ Sex } & \multirow[b]{3}{*}{$\mathrm{p}$-value } & \multicolumn{3}{|c|}{ Age (years) } & \multicolumn{4}{|c|}{ History of RRI* } \\
\hline & & Male & Female & & $\leq 35$ & $35-50$ & $\geq 50$ & & Yes & No & \\
\hline & & $\mathrm{N}=577$ & $\mathrm{~N}=457$ & & $\mathrm{~N}=303$ & $\mathrm{~N}=381$ & $\mathrm{~N}=350$ & $\mathrm{p}$-value & $\mathrm{N}=820$ & $\mathrm{~N}=214$ & $\mathrm{p}$-value \\
\hline \multicolumn{12}{|l|}{ How useful is injury prevention? } \\
\hline Very & 74.1 & 75.0 & 72.9 & \multirow{3}{*}{0.418} & 69.0 & 74.8 & 77.7 & \multirow{3}{*}{0.147} & 76.8 & 63.6 & \\
\hline A little & 25.0 & 23.7 & 26.5 & & 29.7 & 24.4 & 21.4 & & 22.4 & 34.6 & $<0.001$ \\
\hline Not & 1.0 & 1.2 & 0.7 & & 1.3 & 0.8 & 0.9 & & 0.7 & 1.9 & \\
\hline \multicolumn{12}{|c|}{ What is important for injury prevention? } \\
\hline Healthy lifestyle & 44.8 & 45.2 & 44.2 & 0.740 & 44.6 & 42.8 & 47.1 & 0.494 & 43.0 & 51.4 & 0.029 \\
\hline Clothes & 7.6 & 6.6 & 9.0 & 0.152 & 10.9 & 7.9 & 4.6 & 0.010 & 7.7 & 7.5 & 0.919 \\
\hline Shoes & 76.4 & 72.1 & 81.8 & $<0.001$ & 82.2 & 75.1 & 72.9 & 0.015 & 75.7 & 79.0 & 0.320 \\
\hline Progression of the training schedule & 94.4 & 93.9 & 95.0 & 0.473 & 96.7 & 93.7 & 93.1 & 0.110 & 94.6 & 93.5 & 0.505 \\
\hline Technique & 55.8 & 53.2 & 59.1 & 0.059 & 62.7 & 56.7 & 48.9 & 0.002 & 56.3 & 53.7 & 0.495 \\
\hline Surface & 36.5 & 35.5 & 37.6 & 0.484 & 43.9 & 32.0 & 34.9 & 0.004 & 37.3 & 33.2 & 0.263 \\
\hline Other & 7.4 & 9.0 & 5.5 & 0.509 & 4.6 & 6.8 & 10.6 & 0.322 & 7.1 & 8.9 & 0.199 \\
\hline \multicolumn{12}{|c|}{ Do you actively search for injury prevention measures yourself? } \\
\hline Yes & 68.4 & 67.6 & 69.4 & 0.542 & 66.3 & 68.5 & 70.0 & 0.603 & 73.9 & 47.2 & $<0.001$ \\
\hline \multicolumn{12}{|c|}{ Do you take injury prevention measures yourself? } \\
\hline Yes & 81.8 & 80.6 & 83.4 & 0.250 & 78.2 & 82.9 & 83.7 & 0.149 & 86.0 & 65.9 & $<0.001$ \\
\hline \multicolumn{12}{|c|}{ Which injury prevention measures do you take? $^{\dagger}$} \\
\hline Healthier lifestyle & 37.0 & 38.3 & 35.4 & 0.394 & 32.9 & 34.5 & 43.0 & 0.029 & 36.6 & 39.0 & 0.588 \\
\hline Changes to the training schedule & 65.4 & 63.0 & 68.2 & 0.112 & 65.0 & 61.7 & 69.6 & 0.121 & 66.8 & 58.2 & 0.049 \\
\hline Warming-up and cooling-down & 57.8 & 55.9 & 60.1 & 0.219 & 53.6 & 52.5 & 66.9 & $<0.001$ & 57.4 & 59.6 & 0.641 \\
\hline Stretching & 49.8 & 48.0 & 52.0 & 0.246 & 48.5 & 48.4 & 52.2 & 0.582 & 49.2 & 52.5 & 0.479 \\
\hline Changes to clothes & 9.2 & 8.8 & 9.7 & 0.655 & 8.0 & 8.2 & 11.3 & 0.326 & 8.9 & 10.6 & 0.524 \\
\hline Changes to shoes & 41.1 & 32.5 & 51.7 & $<0.001$ & 49.4 & 38.6 & 37.2 & 0.009 & 40.6 & 44.0 & 0.453 \\
\hline Insoles or orthotics & 26.2 & 28.8 & 23.1 & 0.060 & 18.6 & 23.7 & 35.2 & $<0.001$ & 28.4 & 15.6 & 0.002 \\
\hline Bandages, brace or taping & 7.3 & 4.9 & 10.2 & 0.003 & 8.9 & 6.3 & 7.2 & 0.523 & 8.1 & 3.5 & 0.059 \\
\hline Compression socks & 21.4 & 21.9 & 20.7 & 0.672 & 20.3 & 22.2 & 21.5 & 0.864 & 22.3 & 17.0 & 0.165 \\
\hline
\end{tabular}




\begin{tabular}{|c|c|c|c|c|c|c|c|c|c|c|c|}
\hline Changes in running surface & 24.9 & 26.2 & 23.4 & 0.336 & 29.1 & 21.2 & 25.6 & 0.099 & 25.1 & 24.1 & 0.804 \\
\hline Changes in running technique & 24.2 & 27.1 & 20.7 & 0.032 & 21.9 & 24.4 & 25.9 & 0.564 & 25.2 & 19.1 & 0.123 \\
\hline Other & 12.9 & 12.9 & 12.9 & 0.496 & 11.4 & 17.4 & 9.2 & 0.517 & 12.9 & 12.8 & 0.352 \\
\hline
\end{tabular}

${ }^{*}$ Running-related injury; ${ }^{\dagger}$ Only participants who reported to take injury prevention measures $(\mathrm{n}=846)$ were asked this question. 
Table 3. Opinions of the participants (\%) on barriers and facilitators for injury prevention

\begin{tabular}{|c|c|c|c|c|c|c|c|c|c|c|c|}
\hline & \multirow{3}{*}{$\begin{array}{l}\text { All participants } \\
\text { N=1034 }\end{array}$} & \multicolumn{2}{|c|}{ Sex } & \multirow[b]{3}{*}{$\mathrm{p}$-value } & \multicolumn{3}{|c|}{ Age (years) } & \multicolumn{4}{|c|}{ History of RRI ${ }^{*}$} \\
\hline & & Male & Female & & $\leq 35$ & $35-50$ & $\geq 50$ & & Yes & No & \\
\hline & & $\mathrm{N}=577$ & $\mathrm{~N}=457$ & & $\mathrm{~N}=303$ & $\mathrm{~N}=381$ & $\mathrm{~N}=350$ & $\mathrm{p}$-value & $\mathrm{N}=820$ & $\mathrm{~N}=214$ & p-value \\
\hline \multicolumn{12}{|c|}{ What are barriers for injury prevention? $^{\dagger}$} \\
\hline No history of RRI & 34.6 & 28.6 & 43.4 & 0.036 & 33.3 & 36.9 & 33.3 & 0.886 & 1.7 & 86.3 & $<0.001$ \\
\hline No time & 11.7 & 8.0 & 17.1 & 0.058 & 18.2 & 9.2 & 7.0 & 0.118 & 13.9 & 8.2 & 0.237 \\
\hline Not effective & 5.9 & 6.3 & 5.3 & 0.777 & 6.1 & 6.2 & 5.3 & 0.974 & 7.8 & 2.7 & 0.148 \\
\hline Not amusing & 11.7 & 12.5 & 10.5 & 0.679 & 13.6 & 7.7 & 14.0 & 0.461 & 14.8 & 6.8 & 0.099 \\
\hline Not motivated & 20.2 & 21.4 & 18.4 & 0.614 & 22.7 & 12.3 & 26.3 & 0.129 & 25.2 & 12.3 & 0.032 \\
\hline Does not fit in training schedule & 7.4 & 6.3 & 9.2 & 0.448 & 7.6 & 7.7 & 7.0 & 0.989 & 8.7 & 5.5 & 0.413 \\
\hline Not knowing what to do & 45.2 & 46.4 & 43.4 & 0.684 & 48.5 & 43.1 & 43.9 & 0.800 & 59.1 & 23.3 & $<0.001$ \\
\hline Other & 9.0 & 8.1 & 9.2 & 0.447 & 6.1 & 9.2 & 12.3 & 0.422 & 10.4 & 6.8 & 0.555 \\
\hline \multicolumn{12}{|c|}{ What are facilitators for injury prevention? ${ }^{\dagger}$} \\
\hline An injury & 60.1 & 58.0 & 63.2 & 0.482 & 68.2 & 61.5 & 49.1 & 0.095 & 46.1 & 82.2 & $<0.001$ \\
\hline Attractive information & 17.6 & 20.5 & 13.2 & 0.192 & 19.7 & 16.9 & 15.8 & 0.839 & 23.5 & 8.2 & 0.007 \\
\hline Better access to information & 28.7 & 31.3 & 25.0 & 0.353 & 31.8 & 24.6 & 29.8 & 0.645 & 35.7 & 17.8 & 0.008 \\
\hline Integration in daily training & 28.2 & 27.7 & 28.9 & 0.850 & 24.2 & 30.8 & 29.8 & 0.671 & 30.4 & 24.7 & 0.391 \\
\hline More knowledge on effectiveness & 31.9 & 33.9 & 28.9 & 0.472 & 27.3 & 27.7 & 42.1 & 0.141 & 37.4 & 23.3 & 0.043 \\
\hline Also improvement in performance & 28.2 & 30.4 & 25.0 & 0.423 & 27.3 & 24.6 & 33.3 & 0.554 & 26.1 & 31.5 & 0.421 \\
\hline Financial compensation & 5.9 & 7.1 & 3.9 & 0.360 & 15.2 & 0.0 & 1.8 & $<0.001$ & 3.5 & 9.6 & 0.082 \\
\hline Free supplies for injury prevention & 19.1 & 17.9 & 21.1 & 0.585 & 34.8 & 9.2 & 12.3 & $<0.001$ & 23.5 & 12.3 & 0.058 \\
\hline Other & 1.6 & 2.7 & 0.0 & 0.558 & 1.5 & 1.5 & 1.8 & 0.419 & 0.0 & 4.1 & 0.187 \\
\hline \multicolumn{12}{|c|}{ What are your preferred ways to receive information on injury prevention? } \\
\hline Mobile application & 49.3 & 48.0 & 51.0 & 0.342 & 50.2 & 54.9 & 42.6 & 0.004 & 49.4 & 49.1 & 0.933 \\
\hline Website & 45.4 & 49.2 & 40.5 & 0.005 & 44.6 & 44.1 & 47.4 & 0.628 & 44.9 & 47.2 & 0.544 \\
\hline E-mail & 33.3 & 36.4 & 29.3 & 0.017 & 30.0 & 27.6 & 42.3 & $<0.001$ & 34.1 & 29.9 & 0.241 \\
\hline Trainer & 36.6 & 31.0 & 43.5 & $<0.001$ & 39.9 & 33.3 & 37.1 & 0.197 & 37.8 & 31.8 & 0.103 \\
\hline Running store & 15.0 & 11.8 & 19.0 & 0.001 & 22.4 & 14.4 & 9.1 & $<0.001$ & 15.5 & 13.1 & 0.380 \\
\hline Running magazine & 13.7 & 13.2 & 14.4 & 0.556 & 13.2 & 13.9 & 14.0 & 0.950 & 13.9 & 13.1 & 0.757 \\
\hline
\end{tabular}


Health professional

12.9

12.0

14.0

0.329

15.8

10.0

13.4

0.069

14.0

${ }^{*}$ Running-related injury; ${ }^{\dagger}$ Only participants who reported not to take injury prevention measures (n=188) were asked this question. 